\author{
생물학적 모니터링을 이용한 분무기 형태에 따른 \\ 피레스로이드 농약 노출량 평가 \\ 송재석 · 최홍순* · 유호영 · 박병곤 ${ }^{1} \cdot$ 권대호 $^{2}$ \\ 가톨릭관동대학교 의과대학 예방의학교실, ${ }^{1}$ 가톨릭관동대학교 의과대학 생리학교실, \\ ${ }^{2}$ 가톨릭관동대학교 의과대학 미생물학교실
}

\title{
Evaluation of Exposure to Pyrethroid Pesticides according to Sprayer Type using Biological Monitoring
}

\author{
Jae Seok Song, Hong Soon Choi*, Ho Young Yu, Byung Gon Park ${ }^{1}$ and Daeho Kwon ${ }^{2}$ \\ Department of Preventive Medicine, College of Medicine Catholic Kwangdong University, \\ Kangnung, Republic of Korea \\ ${ }^{I}$ Department of Physiology, College of Medicine Catholic Kwangdong University, Kangnung, Republic of Korea \\ ${ }^{2}$ Department of Microbiology, College of Medicine Catholic Kwangdong University, Kangnung, Republic of Korea
}

(Received on October 4, 2016. Revised on October 11, 2016. Accepted on November 17, 2016)

\begin{abstract}
The aim of this study were to evaluate the exposure level of pyrethroid pesticide according to spraying machine type. The urinary metabolites of pyrethroid pesticide in apple farmers were analyzed to determine the exposure level of pyrethroid pesticide. The result shows that, the spraying volume was greater in SS sprayer group than in power sprayer group. But multi variate analysis which adjust spraying volume and field area, there were no difference of urinary metabolites between two sprayer machine. To make more accurate model of pesticide exposure, the factors influencing pesticide exposure should be determined and further study should be done.
\end{abstract}

Key words GC/MSD, power sprayer, pyrethroids insecticides, speed sprayer, urine

\section{서 론}

농약 노출을 평가하는 것은 농약과 건강장해에 대한 연구 를 하는데 있어서 필수적이다. 농약 노출을 평가하는 방법 (Fensker와 Day JR, 2005; Lewis, 2005; Franklin과 Worgan, 2005; Chester, 2010)은 크게 외적노출(external exposure)을 평가하는 것과 내적노출(internal exposure)을 평가하는 것으 로 나눌 수 있다. 외적노출을 평가하는 것으로는 기중 평가 나 피부패치법 등이 있다. 기중 평가방법은 개인 시료포집 기에 흡착관을 붙여 작업자의 호흡기 위치에서 농약 원제를 평가하는 방법이다. 내적노출을 평가하는 방법은 생체시료 에서 농약의 대사물질을 측정하여 농약 노출량을 평가하는

\section{*Corresponding author}

E-mail: wesang@cku.ac.kr
방법(Fensker와 Day JR, 2005)으로 노출 경로와 무관하게 전체 노출량을 평가할 수 있다는 장점이 있으나, 시료 채취 시간이 잘 맞아야 하고 분석의 어려움이 있다고 하는 문제 점이 있다(KSOEM, 2014). 외적노출을 평가하는 방법은 호 흡기 폭로만을 반영하거나 피부노출을 평가하는 방법(Fensker 와 Day JR, 2005; Hughes et al., 2008; Chester., 2010)이 있지만, 시료채취의 어려움이 있어서 직접적인 평가방법은 농약과 건강장해에 대한 대규모 역학연구에서 사용하기에는 부적절하다. 때문에 농약노출에 영향을 미칠 수 있는 요인 을 파악하고, 그 요인에 따라 노출량을 추정하는 간접적인 방법인 생물학적 모니터링이 농약으로 인한 건강장해의 연 구에서 가장 타당하다고 할 수 있으며, 국내에서도 생물학 적모니터링을 이용하여 농약 노출을 평가한 연구가 진행되 고 있다(Kim et al., 2015; Song et al., 2014).

우리나라의 경우, 농약 살포 방법은 외국과 매우 다르다. 
우리나라에서는 대부분의 경우, 동력분무기를 사용하지만 과수원과 같이 높은 곳의 목표점까지 농약을 살포하기 위해 서는 speed sprayer (이하 SS기)를 사용한다. SS기는 넓은 면적을 빠르게 농약을 살포할 수 있을 뿐 아니라 높은 압력 을 낼 수 있어서 농약을 넓고 높은 곳 까지 살포할 수 있다 는 장점이 있어서 과수원 등에서 많이 사용하고 있다. 그러 나 $\mathrm{SS}$ 기의 경우에, 높은 곳에 농약을 살포한 후, 엽면에 묻 지 않은 농약은 살포자에 다시 떨어지기 때문에 농약의 피 부노출이 많을 수 있는 가능성이 있다. 다시 떨어지는 농약 을 막기 위해 캐노피가 설치된 SS기도 시판되고 있지만, 캐 노피의 경우, 가지에 걸리기 때문에 농업인들이 기피를 하 고 있다. 한 연구에서는 과수작업에서 캐노피 설치 유무에 따른 유기인계 노출량 평가에서 캐노피가 있는 경우 캐노피 가 없는 경우보다 노출량이 상대적으로 낮게 나타났다(Lee et al., 2016). 과수농가의 $64.9 \%$ 가 SS기를 사용하고 $33.9 \%$ 가 동력분무기를 사용하고 있다(Hong et al., 2007.) SS기는 농약 노출량이 많다고 알려져 있다. 또한 노출량을 평가하 는 실험결과에서도 $\mathrm{SS}$ 기가 농약 노출이 많다고 하는 연구 결과가 있지만, 이는 $\mathrm{SS}$ 기가 보다 넓은 면적을 살포하고 더 많은 농약을 살포하기 때문인지, 아니면 SS기 자체가 동력 분무기 보다 인체의 농약노출이 많은지에 대한 실증적 연구 는 부족한 편이다.

농약노출의 평가는 통제된 상태에서 평가할 수도 있으나, 농약 노출을 평가하는 이유 중 하나가 농약노출로 인한 급 만성 건강장해를 규명하기 위한 역학적 연구의 기초자료 제 공이라는 점을 감안하면 실제 농작업자들의 농약살포작업으 로 인한 농약노출량을 통제하지 않은 상태로 평가하는 것은 매우 중요하다고 할 수 있다.

그러나 정작 노출량이 많은지에 대한 실증적인 연구는 부 족한 형편이다. 때문에 본 연구는 동일한 작목(사과)을 대상 으로 동력분무기와 $\mathrm{SS}$ 기를 사용하는 사람들을 대상으로 농 약 노출량을 평가하고자 하였다.

\section{재료 및 방법}

\section{연구방법}

본 연구는 사과 주생산지인 경북 $\mathrm{Y}$ 시에 소재한 마을에 사과 작물을 대상으로 하였다. 선정 과정은 지역 농업기 술센터 자문을 구해 사과작물을 주로 재배하는 마을을 추 천받아 해당 마을 이장님의 협조를 구하여 시행하였다. 조사방식은 관행적으로 실제 농가에서 살포하는 방식에 따라 $\mathrm{SS}$ 살포기 $(n=9)$, 동력분무기 $(n=13)$ 를 사용하여 총 22 명을 조사대상으로 시행하였다. 시료채취는 농약 살포 를 한 다음날 아침 첫 소변을 채취하였고, 시료는 냉장 상태로 운반 후 분석시 까지 $-20^{\circ} \mathrm{C}$ 냉동 보관하여 사용하 였다. 생물학적 모니터링을 위한 시료 분석 방법은 송 등 의 연구에서 시행한 방법을 이용하였다(Song et al., 2014). 생물학적 모니터링 대상물질은 피레스로이드계 살 충제를 이용하였으며 대사산물 중에서 cis-DCCA, trans$\mathrm{DCCA}, \mathrm{DBCA}$ 를 모두 더해서 전체 피레스로이드계 살충 제의 노출량을 평가하였다. 노출량에 영향을 미치는 요인 을 분석하기 위해서 기후요인, 살포량, 살포면적 등을 조 사하였다.

\section{실험 재료}

2-phenoxybenzoic acid (2-PBA; 98\%, Fluka), cis-and trans-3-(2,2-Dichlorovinyl)-2,2-dimethylcyclopropane carboxylic acid (cis-and trans-DCCA; 99\%, Cambridge isotope), is-3-(2,2-Dibromovinyl)-2,2-dimethyl cyclopropane carboxylic acid (cis-DBCA; 99\%, Dr. Ehrenstorfer)를 사용 하였다. 유도체 시약은 MTBSTFA (N-tert-Butyldimethylsiyl$\mathrm{N}$-methyltrifluoroacetamide; $98 \%, \mathrm{TCI}$ 를 사용하였다. 기타 용매로 사용한 n-hexane, toluene은 HPLC grade를 사용 하 였다.

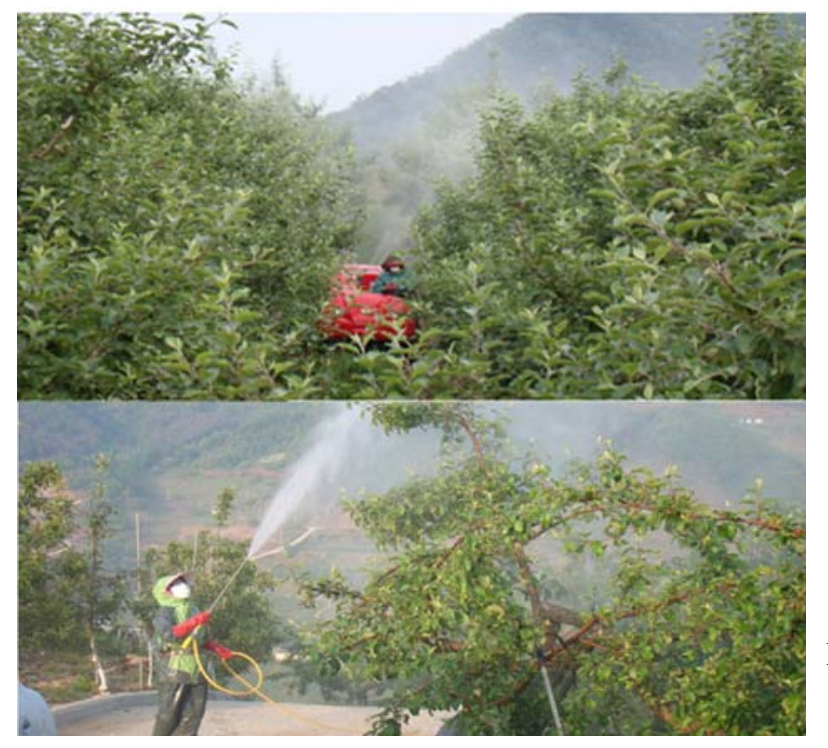

Fig. 1. Application of pesticide with speed 


\section{시료 전처리}

대사물질 전처리 방법은 Schettgen 방법을 참고하여 사용 하였다(Schettgen et al., 2002). 소변시료를 상온에 방치하 여 해동 후 $12 \mathrm{~mL}$ 를 conical tube에 넣어 원심분리 후 그중 상층액 $10.0 \mathrm{~mL}$ 를 screw cap tube에 취한 다음, $\mathrm{HCl}(37 \%)$ $1 \mathrm{~mL}$, 내부표준물질 2-PBA ( $1 \mathrm{mg} / \mathrm{l}) \quad 100 \mu \mathrm{l}$ 를 첨가하여 water bath에서 $90^{\circ} \mathrm{C}, 1$ 시간 동안 가수분해한 후 상온에 식 혔다. 추출용매 $\mathrm{n}$-hexane $5 \mathrm{~mL}$ 를 넣고, 10 분 동안 흔든 후 원심분리 $(1500 \mathrm{~g} \times 5 \mathrm{~min})$ 하여 상층액을 다른 시험관에 옮겼 다. 다시 $\mathrm{n}$-hexane $5 \mathrm{~mL}$ 를 넣고 재추출하여 상층액을 취하 였다. 2번의 추출과정에서 얻은 유기층을 시험관에 담아 $\mathrm{N}_{2}$ 가스로 건조 하여 완전히 날린다. 유도체 과정은 시험관에 toluene $50 \mu \mathrm{l}$, MTBSTFA $10 \mu \mathrm{l}$ 를 첨가한 후 중탕에서 $70^{\circ} \mathrm{C}, 45$ 분 동안 반응 과정을 거친 후 상온에서 식혔다. 이 반응액 중 $2 \mu 1$ 를 $\mathrm{GC} / \mathrm{MSD}$ 로 분석하였다.

정량분석은 $\mathrm{GC} / \mathrm{MS}$ 를 이용하여 각 크로마토그램의 피크 면적을 내부표준물질 면적비로 나누어 검량선을 작성 하였 고(Song et al., 2014), 대사물질 농도 값은 크레아티닌으로 보정하여 사용하였다. 크레아티닌 분석은 임상의학 연구소 인 선함에 의뢰하였고, 사용한 분석방법은 Jaffe법을 이용하 였다(Jaffe, 1886).

\section{GC/MSD 분석조건}

가스크로마토그라피 분석은 Hewlett-Packard 5890 Gas Chromatograph (GC)에 direct interface로 연결된 HP 5973 Mass Spectrometer이고, 시료주입은 HP 7673A Autosampler 그리고 split/splitless 인젝터에서 splitless 모드를 사용하였 다. purge off 시간은 1 분, 주입구 온도는 $250^{\circ} \mathrm{C}$ 검출기 온 도는 $280^{\circ} \mathrm{C}$ 로 설정하였다.

크로마토그라피 분리는 Rtx65 capillary column (30 mx $0.25 \mathrm{~mm} \times 0.25 \mathrm{um}$ )을 사용하였다. GC-MSD에서 ion mass 중 밑줄 친 ion이 가장 큰 abundance를 나타내고 있지만 정 성 분석시 크로마토그램의 최적의 분리도를 위해 선택적으 로 이온을 설정하여 분석하였다. 본 연구에 사용되었던 $\mathrm{GC} /$ $\mathrm{MSD}$ 분석조건은 Table 1 과 같다.

\section{통계분석방법}

살포량, 살포면적, 살포시간 등은 현장에서 직접 조사하였 으며, 풍속과 습도는 기상청자료를 이용하였다. 피레스로이 드계 살충제의 대사물질은 $\mathrm{DBCA}$ 와 cis/trans $\mathrm{DCCA}$ 를 합 하여 계산하였다. 두 군간의 비교는 student t-test를 이용하 였다.

살포량이나 살포면적이 아니라 순수하게 살포기계 만의 영향을 보기 위하여 살포량, 살포면적, 기후조건 등을 보정 한 상태에서 다변량 회귀분석을 실시하였다. 분석은 $\mathrm{SAS}$ 9.4 for windows를 이용하였고, 유의 수준의 0.05 로 하였다.
Table 1. The operating conditions of GC/MSD for pyrethroid pesticides

\begin{tabular}{|c|c|c|}
\hline \multicolumn{2}{|c|}{ Description } & Conditions \\
\hline \multicolumn{2}{|c|}{ Detector Temp } & $280^{\circ} \mathrm{C}$ \\
\hline \multicolumn{2}{|c|}{ Injector Temp } & $250^{\circ} \mathrm{C}$ \\
\hline \multicolumn{2}{|c|}{ Injection volume } & $2 \mu \mathrm{l}$ \\
\hline \multicolumn{2}{|c|}{ Column } & $\operatorname{Rtx} 65(30 \mathrm{~m} \times 0.25 \mathrm{~mm} \times 0.25 \mathrm{um})$ \\
\hline \multicolumn{2}{|c|}{ Gas flow rate } & $1 \mathrm{ml} / \mathrm{min}$ \\
\hline \multicolumn{2}{|c|}{ Oven Temp } & $\begin{array}{l}80^{\circ} \mathrm{C}, 1 \mathrm{~min}, 10^{\circ} \mathrm{C} / \mathrm{min} \text { to } 150^{\circ} \mathrm{C} \text {, } \\
1 \mathrm{~min} \text { and } 15^{\circ} \mathrm{C} \text { min to } 300^{\circ} \mathrm{C} \text { for } \\
6 \mathrm{~min}\end{array}$ \\
\hline \multicolumn{2}{|l|}{ Scan } & $1.2 \mathrm{scan} / \mathrm{sec}$ \\
\hline \multicolumn{2}{|c|}{ Electron Impact } & $70 \mathrm{ev}$ \\
\hline \multicolumn{2}{|c|}{ Purge off } & $1 \mathrm{~min}$ \\
\hline \multicolumn{2}{|c|}{ MS range } & $50-500$ \\
\hline \multicolumn{2}{|c|}{ Solvent delay } & $5 \mathrm{~min}$ \\
\hline \multicolumn{2}{|c|}{ Split ratio } & splitless \\
\hline Group & Start Time (min) & Selected Ion (m/z) \\
\hline 1 & 12.00 & 265 \\
\hline 2 & 14.00 & 355 \\
\hline 3 & 16.60 & 271,211 \\
\hline
\end{tabular}

Table 2. The spraying characteristics between Speed sprayer and power sprayer

\begin{tabular}{lcc}
\hline & Power sprayer & Speed sprayer \\
\hline Spray volume (L) & $2615.4 \pm 1340.9$ & $3222.2 \pm 618$ \\
Humidity (\%) & $70.8 \pm 15.9$ & $80.8 \pm 15.6$ \\
Wind speed (m/s) & $2.2 \pm 0.9$ & $2 \pm 1.1$ \\
Spraying time (min) & $180 \pm 64.2$ & $180 \pm 32.8$ \\
Spraying area $\left(\mathrm{m}^{2}\right)^{\mathrm{a})}$ & $2769.2 \pm 1423.3$ & $4455.6 \pm 1480.8$ \\
Metabolites of & $263.9 \pm 300$ & $279.4 \pm 509.3$ \\
pyrethroid (ug/g cre) & & \\
\hline a) $\mathrm{p}<0.05$ & &
\end{tabular}

\section{결과 및 고찰}

$\mathrm{SS}$ 기를 사용하는 군(n=9)에서 동력분무기를 사용하는 군 $(\mathrm{n}=13)$ 에 비해서 살포면적이 $4455.6 \mathrm{~m}^{3}$ 로 동력분무기 사용 군인 $2769.2 \mathrm{~m}^{3}$ 에 비해서 통계적으로 유의하게 넓었다 $(\mathrm{p}<$ $0.05)$. 살포량은 $\mathrm{SS}$ 기 사용군이 $3222.2 \pm 61.8$ 로 동력분무기 $2615.4 \pm 1340.9$ 보다 많았으나 통계적 유의성은 없었고, 살포 시간도 각각 $180 \pm 32.8$ 분, 180.64 .2 분으로 유의한 차이를 보 이지 않았다 $(\mathrm{p}>0.05)$.

생물학적 모니터링 결과, $\mathrm{SS}$ 기를 사용하는 군에서 피레스 로이드계 살충제는 $279.4 \pm 509.3 \mu \mathrm{g} / \mathrm{g} \mathrm{Cre}$ 이었으며 동력분 무기를 사용하는 군에서는 $263.9 \pm 300 \mu \mathrm{g} / \mathrm{g} \mathrm{Cre}$ 으로 통계적 인 차이는 없었다 $(\mathrm{p}>0.05)($ Table 2$)$.

피레스로이드계 살충제의 대사물질을 종속변수로 하는 다 
Table 3. The result of multiple regression analysis of the factors that affect the urinary metabolite of pyrethroid pesticide

\begin{tabular}{lccc}
\hline Variable & Regression coefficient & $\mathrm{t}$ Value & $\operatorname{Pr}>|\mathrm{t}|$ \\
\hline Intercept & 1317.86553 & 3.13 & 0.0064 \\
Spray type (0=power spray, 1=Speed spray) & 109.63541 & 0.74 & 0.4718 \\
Spray volume & 0.20304 & 2.87 & 0.0110 \\
Humidity & -19.08652 & -4.21 & 0.0007 \\
Wind speed & -119.65819 & -1.71 & 0.1073 \\
Spraying area & -0.03058 & -0.59 & 0.5652 \\
\hline
\end{tabular}

중회귀분석의 결과 $\mathrm{SS}$ 기를 사용하는 농작업자는 동력분무 기를 사용하는 농작업자에 비해서 109.64 만큼 대사물질이 많이 나왔지만, 통계적인 유의성은 없었다 $(\mathrm{p}=0.4718)$. 반면 살포량 $(\beta=0.203, \mathrm{p}=0.01101)$, 습도 $(\beta=-19.09, \mathrm{p}=0.0007)$ 가 통계적 연관성을 나타냈다.

따라서 SS기는 동력분무기에 비해서 살포량이 많아서 농 약노출이 많다고 볼 수 있으며, 살포량이 동일하다고 가정 을 하였을 때에는 살포기의 종류는 농약 노출에 영향을 미 치지 않는다는 것을 알 수 있다(Table 3).

본 연구결과, $\mathrm{SS}$ 기를 이용한 농약 살포자는 살포량이 동 력분무기에 비해서 많았다. 이러한 경우, 살포기의 특징에 따른 농약 노출을 평가하기 위해서는 혼란변수라고 할 수 있는 살포면적이나 살포량을 통제해야 한다.

본 연구에서 시행한 다변량분석인 회귀 분석의 경우, 다 른 혼란변수를 통제한 상태에서 단일 변수의 영향을 볼 수 있는 통계적 방법이다(Kim et al., 2000). 분석결과, 살포면 적은 피레스로이드계 살충제의 노출에 영향을 미치지 않았 으며 살포량의 경우, 살포량이 1리터 증가할 때 마다 피레 스로이드계 살충제의 대사물질이 0.2 만큼 증가한다는 것을 알 수 있었다. 반면 습도의 경우에는 습도가 높을수록 대사 물질의 양이 통계적으로 유의하게 감소하였다. 습도가 높은 경우에는 농약의 휘발량이 적어지고 이로 인해서 가스상태 의 농약이 호흡기로 노출되는 양이 감소할 수 있다(Damalas et al., 2011). 그러나 농약의 경우, 피부노출이 중요하다고 알려져 있으며(Choi et al., 2006) 이에 대해서는 추후 연구 가 필요하다고 할 수 있다. 2016년 작물별 노출정도를 보기 위해 우리나라 대표적인 밭작물인 사과, 고추, 무 그리고 대 파를 대상으로 피레스로이드 살충제 노출평가에서 사과에서 노출량이 가장 높게 나타났다(Song et al., 2016). 연구결과, 농약 노출은 살포기의 종류가 아니라 작물의 특성에 영향을 많이 받으며 그 외, 기후특성에도 영향을 받는 다는 것을 알 수 있었다. 이는 추후 농약 노출에 대한 연구를 진행하는데 있어서 중요한 결과라고 할 수 있다.

\section{감사의 글}

본 연구는 농촌진흥청 국립농업과학원 유해화학물질 안전
관리기술 개발 연구과제인 ‘농약노출과 만성퇴행성 질환의 연관성 규명'의 일환으로 수행되었습니다(과제번호 : PJ010009).

\section{Literature Cited}

Chester, G. (2010) Worker exposure: Methods and Techniques. Hayes Handbook of pesticide Toxicology. pp.1127-1137, (ed. W.J.Heys) Elsevier., U.S.A.

Choi, H., J. K. Moon, K. H. Liu, H. W. Park, Y. B. Ihm, B. S. Park and J. H. Kim (2006) Risk assessment of human exposure to cypermethrin during treatment of mandarin fields. Archives of Environmental Contamination and Toxicology, 50(3):437-442.

Damalas, C. A. and I. G. Eleftherohorinos (2011) Pesticide exposure, safety issues, and risk assessment indicators. International Journal of Environmental Research and Public Health, 8(5):1402-1419.

Fenske, R. A. and F. W. Day JR (2005) Assesment of exposure for pesticide handlers in agricultureal, Residential and institutional environments. pp.11-43, in occupational and residential exposure assesment for pesticides, JohnWiley and Sons., U.S.A.

Franklin, C. A. and J. P. Worgan (2005) Occupational and residential exposure assesment for pesticides.

Hong, S. S., J. B. Lee, Y. K. Park, J. S. Shin, G. J. Im and G. H. Ryu (2014) The proposal for pesticide exposure estimation of Korean orchard farmer, Korean J. Pestic. Sci. 11(4):281288.

Hughes, F. A., A. P. Flores, L. M. Ramos, A. Zalts, C. R. Glass and J. M. Montserrat (2008) Potential dermal exposure to deltamethrin and risk assesment for manual sprayer: Influence of crop type, Science of The Total Environment. 391(1):34-40.

Jaffe, M. Z. (1886) About the precipitation caused by pikrinic acid in normal urine and about a new reaction of creatinine. Physiol Chem, 10:391-400.

Korean Society of Occupational \& Environmental Medicine (2014) occupational \& environmental medicine.: pp.738746 Gyechuk Munwasa., KOREA.

Kim. D.S., N. J. Kang (2000) Regression analysis. pp.28-37, Nanam., KOREA.

Kim, H. K., J. S. Song, H. S. Choi and H. Y. Yu (2015) 
Evaluation of Exposure to Pyrethroid Pesticides in Highland Cabbage Farmers by Using Biological Monitoring, Korean J. Pestic. Sci, 19(1):41-46.

Lewis, R. G. (2005) Residental post application pesticide exposure monitoring, In: Occupational and Residential exposure assesment for pesticides, edited, 71-128.

Lee, J. Y., S. C. Roh (2016) Evaluation of exposure to organophosphorus pesticides according to application type and protective equipment among farmers in south Korea,
Korean J. Pestic. Sci. 20(2):172-180.

Song, J. S., K. D. Kwon, H. S. Choi and H. Y. Yu (2014) Biological Monitoring of the Exposure Level of Organophosphorus and Pyrethroid Pesticidesin Floriculture Workers and Florists, Korean J. Pestic. Sci. 18(1):41-47.

Song, J. S., H. S. Choi and H. Y. Yu (2016) Assessment of pesticide exposure by crops by Biological Monitoring, The Korea society of occupational and environmental medicine.

\section{생물학적 모니터링을 이용한 분무기 형태에 따른 피레스로이드 농약 노출량 평가}

송재석 · 최홍순 $*$ 유호영 · 박병곤 ${ }^{1} \cdot$ 권대호 $^{2}$

가톨릭관동대학교 의과대학 예방의학교실, ${ }^{1}$ 가톨릭관동대학교 의과대학 생리학교실,

${ }^{2}$ 가톨릭관동대학교 의과대학 미생물학교실

요 약 이 연구의 목적은 살포기의 종류에 따른 피레스로이드 농약의 노출량을 평가하고자 하였다. 피레스로이드 계 농약의 노출을 평가하기 위하여 사과 농작업자의 소변중 피레스로이드계 농약의 대사물질을 평가하였다. 결과에 서는 살포량이 $\mathrm{SS}$ 기 살포 그룹이 동력분무기 그룹보다 높았다. 하지만, 살포량과 살포면적을 통제하기 위하여 다변 량 분석법으로 분석한 결과 SS기 살포자와 동력분무기 살포자의 노출량은 차이가 없었다. 농약노출에 대한 정확한 모델을 만들기 위해서는 농약 노출에 관련된 인자들이 통제되어야하고 추가적인 연구가 필요하다고 할 수 있다.

색인어 가스크로마토그라피/질량분석기, 동력분무기, 피레스계 살충제, $\mathrm{SS}$ 기, 소변 